\section{P220 OPPORTUNITIES AND CHALLENGES TO THE RITUALS OF CARE THAT CIRCUMVENT MISDIAGNOSIS AMONGST RAPID HIV TESTERS IN ZIMBABWE}

${ }^{1}$ Morten Skovdal* ${ }^{2}$ Nadine Beckmann, ${ }^{3}$ Rufurwokuda Maswera, ${ }^{4}$ Constance Nyamukapa, ${ }^{4}$ Simon Gregson. 'University of Copenhagen, Department of Pubic Health, Copenhagen, Denmark; ' University of Roehampton, London, UK; ${ }^{3}$ Biomedical Research and Training Institute, Harare, Zimbabwe; ${ }^{4}$ Imperial College London, Department of Infectious Disease Epidemiology, London, UK

10.1136/sextrans-2019-sti.364

Background There is uncertainty associated with all medical testing and diagnosis. However, a growing number of studies highlight disconcerting levels of misdiagnosis in the scale-up of HIV rapid testing programmes. Evaluation studies point to user errors as potential sources of misdiagnosis, yet very little has been done to understand the views and experiences of clinicians and primary counsellors who perform rapid HIV testing.

Methods This study draws on interviews with 28 health facility staff who perform rapid HIV tests on a daily basis. The testers were recruited from 11 health facilities across Zimbabwe, eight of which have above average rates of misdiagnosis. Interviews were translated, transcribed and thematically interrogated.

Results Reflecting on their rapid HIV testing practices, potential sources of misdiagnosis included uncertainties associated with new testing algorithms and test kits; reading test results too quickly or too late; misreading of test results if the test produces faint or unclear lines; and failure to record and document test results accurately. Anxiety about potentially making such mistakes and the resulting feelings of guilt and self-blame in the case of a wrong diagnosis being handed out meant that testers found comfort in complying with standard operating procedures and associated quality controls. Misdiagnosis was thus portrayed as a result of deviating from 'rituals of care'. The testers located deviance from the procedures in the wider context of high workloads and growing demands for HIV testing, arguing that distractions, and HIV test kit stock-outs occasionally made it difficult for testers to follow the procedures.

Conclusion Rather than attributing misdiagnosis to malfunctioning test kits or complicated standard operating procedures, testers saw misdiagnosis largely as human error - failure to follow laid out procedures. Their recognition of how a resource-depleted work and HIV testing environment can contribute to misdiagnoses, highlight the need to adequately resource HIV rapid testing programmes.

Disclosure No significant relationships.

\section{P222 LIVING WITH HIVIAIDS IN ADOLESCENCE: FACTORS FOR ADHERENCE TO THERAPEUTICS}

'Shirley Coelho*, ${ }^{2} J u l i a$ Yaeko Kawagoe. ${ }^{1}$ Centro Estadual Especializado Em Diagnóstico, Assistência E Pesquisa e IST, HIVIAIDS e Hepatites Virais, Ambulatório De Virologia, Salvador, Brazil; ${ }^{2}$ Faculdade Israelita de Ciências da Saúde Albert Einstein, São Paulo, Brazil

10.1136/sextrans-2019-sti.365

Background Coelho SJ. Living with HIV/AIDS in adolescence: factors for adherence to therapeutics. Dissertation (Master Degree)- Faculdade Israelita de Ciências da Saúde Albert Einstein - (FICSAE) Israeli College of Health Sciences Albert Einstein, São Paulo, 2019. 126f.
Methods Descriptive, qualitative and exploratory research with adolescents (10-19 years old) under treatment for HIV, in the unit that sets the benchmark for the treatment of HIV/AIDS in Salvador-Ba. EI: evaluation of database on adherence and socio-demographic characteristics of adolescents. EII: collection, through electronic chart, of information on sexual awakening, diagnosis and treatment. EIII: interview with the adolescents. For the analysis of data, it was used the technique of Bardin Content Analysis and the Health Beliefs Method.

Results The analysis of reviews resulted in four categories: perception of susceptibility to HIV, perception on the severity of HIV, noticed benefits ad barriers for the adherence to treatment. The lack of knowledge on HIV/AIDS, and unsafe sexual practices because of trust in the partner and/or stable relationships, showed low susceptibility to HIV/AIDS. Under the perception on the severity, they related the disease to critical condition and death; and that using illicit drugs and the religious extremism related to the cure, can alter the perception on the severity of AIDS. Support from the family, school, friends and health services, faith and religious practices were reported as fundamental for the treatment. Absence of family support and lack of discussions on the topic in schools, beyond prejudice and discrimination from friends, abusive use of drugs and extreme religiosity were factors that were said to hinder the treatment.

Conclusion There i slack of knowledge regarding HIV/AIDS with low perception of susceptibility in the acquisition of the virus. They highlighted the importance of the family, friends, school, faith and religious practices, and the work of the professionals for the adherence of the treatment.

Disclosure No significant relationships.

\section{P223 PREVALENCE OF REPRODUCTIVE TRACT INFECTIONS AND HIV ON PREGNANT WOMEN IN SOME AREAS IN INDONESIA, 2016-2017}

${ }^{1}$ Luxi Pasaribu*, ${ }^{2}$ Sunarno Sunarno, ${ }^{2}$ Nur Hariastuti, ${ }^{3}$ Trijoko Yudopuspito, ${ }^{4}$ Sjaiful Fahmi Daili, ${ }^{5}$ Muhammad Alamsyah Aziz. 'National Institute of Health Research and Development, MOH Republic of Indonesia, Center for Public Health Efforts, Jakarta Pusat, Indonesia; ${ }^{2}$ National Institute of Health Research and Development, $\mathrm{MOH}$ Republic of Indonesia, Center for Biomedical and Basic Health Technology, Jakarta, Indonesia; ${ }^{3}$ Directorate of Direct Transmission Disease Control, MOH Republic of Indonesia, Directorate Generale of Disease Control and Prevention, Jakarta, Indonesia; ${ }^{4}$ Faculty of Medicine, Universitas Indonesia, Jakarta, Indonesia; ${ }^{5}$ Universitas Padjajaran, Bandung, Indonesia

\subsection{6/sextrans-2019-sti.366}

Background Control and prevention of Reproductive Tract Infections (RTI), including Sexually Transmitted Infections (STI) and HIV, is principal during pregnancy. The infections prevalence data of Indonesia general population is still rare, while the number of housewives having HIV arising. We conducted research about the prevalence of RTIs and HIV in pregnant women in some parts of Indonesia to understand the circumstantes.

Methods The cross-sectional research conducted 2016-2017 in Pekanbaru City, Tangerang District, Bandung City, and Kupang City. There were 170 respondents in each site who were taken from the Mother-Neonatal-Children-Health clinics on chosen Public Health Centers. Data collection accomplished with local team through interview, biomedical sample collection, and laboratory analysis. The microbial pathogen tested were Gonorrhea, Chlamidiasis, Syphilis, Trichomoniasis, Bacterial Vaginosis, Candidiasis, Herpes simplex-2, and HIV. Also, we collected behavior, demographic, and pregnancy checkups 